\title{
Características fisiológicas e ecológicas de isolados de rizóbios oriundos de solos ácidos de Iranduba, Amazonas
}

\author{
Francisco Adilson dos Santos Hara ${ }^{(1)}$ e Luiz Antonio de Oliveira(2)
}

\begin{abstract}
(1)Universidade Federal do Amazonas, Fac. de Ciências Agrárias, Dep. de Eng. Agrícola e Solos, Avenida General Rodrigo Octávio Jordão Ramos, no 3000, Bairro Coroado, CEP 69077-000 Manaus, AM. E-mail: fhara@ufam.edu.br (2)Instituto Nacional de Pesquisas da Amazônia, Coordenação de Pesquisa em Ciências Agronômicas, Caixa Postal 478, CEP 69011-970 Manaus, AM. E-mail: luizoli@inpa.gov.br
\end{abstract}

Resumo - O alumínio e a acidez dos solos da Amazônia podem diminuir a população de rizóbios que fixam o nitrogênio, solubilizam fosfatos pouco solúveis e aumentam a disponibilidade do fósforo em sistemas produtivos. O objetivo deste trabalho foi avaliar a capacidade nodulífera, tolerância à acidez e ao alumínio, bem como a capacidade de solubilizar fosfatos insolúveis de isolados de rizóbios, obtidos de amostras de solos agrícolas do Município de Iranduba, AM. As amostras de solos apresentavam isolados de rizóbios com potencialidades para serem utilizados como fonte de inóculos para o caupi, de cujos nódulos foram extraídos para testes de tolerância e solubilização. O inóculo INPA-M10 tendeu a superar todos os demais quanto ao rendimento da biomassa seca da parte aérea das plantas. Houve correlação significativa entre o número e massa dos nódulos, o que indica que os isolados apresentaram nódulos de tamanho semelhante. A sensibilidade à acidez e ao alumínio foi apresentada por $43 \%$ dos isolados; os demais se comportaram como tolerantes. A solubilização de fosfatos de cálcio foi observada na presença de $57 \%$ dos isolados. Nessa mesma proporção também foram encontrados isolados que solubilizaram fosfato de alumínio.

Termos para indexação: nitrogênio, acidez, alumínio, solubilização de fosfatos.

\section{Physiological and ecological characteristics of rhizobia isolates from acid soils of Iranduba, Amazonas}

\begin{abstract}
Aluminum content and acidity of Amazonian soils may decrease the population of rhizobia, which fix $\mathrm{N}_{2}$, solubilize insoluble phosphates, and increase the availability of $\mathrm{P}$ in the productive systems. The aim of this work was to evaluate the nodulation capacity, tolerance to acidity and to toxic aluminum, as well as the capacity to solubilize calcium and aluminum phosphates of rhizobia isolates obtained from farm soil samples of Iranduba, AM, Brazil. Soil samples were used as source of inocula for cowpea bean, and isolates were extracted from the nodules, in order to test tolerance and solubilization. Soil samples presented populations of rhizobia with potential to be used as source of inocula for cowpea. INPA-M10 tended to surpass all other inocula in relation to the shoot dry matter yield. There was a significant correlation between the number and mass of the nodules, indicating that isolated rhizobia presented nodules of similar sizes. The sensibility to acidity and aluminum was showed by $43 \%$ of the isolated rhizobia; the other presented itself as tolerant. The solubilization of calcium phosphate was observed in the presence of $57 \%$ of isolated rhizobia. The same proportion occurred in the solubilization of aluminum phosphate.
\end{abstract}

Index terms: nitrogen, acidity, toxic aluminum, phosphate solubilizing.

\section{Introdução}

A alta lixiviação de bases trocáveis, na maioria dos solos de terra firme da Amazônia, propicia diminuição do pH e aumenta a solubilização do $\mathrm{Al}^{3+}$ (Sanchez et al., 1982). Além disso, há deficiência de N, elemento essencial para a planta e de difícil aplicação como fertilizante pelos agricultores regionais (Sanchez et al., 1982).
Nesse contexto, a utilização do rizóbio é um processo chave para o manejo agrícola sustentável na Amazônia, a fim de proporcionar às plantas menor dependência da aplicação de fertilizantes químicos, pois além da capacidade de fixar nitrogênio, algumas estirpes são capazes de solubilizar fosfatos pouco solúveis do solo, e disponibilizam o fósforo tanto para si como para a plan- 
ta hospedeira, promovendo o crescimento das mesmas (Starkanova et al., 1999).

Fatores predominantes nos solos da Amazônia, como pH ácido e alta concentração de alumínio tóxico, podem diminuir a população desses microrganismos no solo (Octive et al., 1994; Wood, 1995; Hungria \& Vargas, 2000). No entanto, algumas estirpes podem desenvolver mecanismos de tolerância a esses fatores estressantes (Kawai et al., 2000; Watkin et al., 2000). A utilização dessas estirpes tolerantes pode aumentar a fixação biológica em solos ácidos e reduzir a aplicação de nitrogênio e fósforo, de acordo com os princípios da agricultura ecológica e economicamente sustentável.

O presente trabalho teve como objetivo avaliar a capacidade nodulífera e fixadora de nitrogênio, a tolerância à acidez e ao alumínio tóxico, e a capacidade de solubilizar fosfatos de cálcio e de alumínio de isolados de rizóbios, de amostras de solos agrícolas ácidos da comunidade rural de Manairão, Município de Iranduba, AM.

\section{Material e Métodos}

\section{Avaliação da efetividade dos isolados de rizóbios nas amostras de solos}

Em cinco propriedades rurais da comunidade de Manairão, localizada no Município de Iranduba, AM, quatro a cinco áreas com diferentes cultivos agrícolas foram selecionadas e, de cada uma delas, retiraram-se três amostras superficiais de $0-20 \mathrm{~cm}$ de solos, totalizando 30 amostras. Em todas as propriedades, o solo foi classificado como Latossolo Amarelo. Os valores de $\mathrm{pH}\left(\mathrm{H}_{2} \mathrm{O}\right)$ das amostras de solo estão apresentados na Tabela 1.

Tabela 1. Valores médios de $\mathrm{pH}$ das amostras de solo, coletadas em propriedades rurais de Iranduba, AM, utilizadas como fonte de inóculo de rizóbio.

\begin{tabular}{clccccc}
\hline Propriedade & \multicolumn{1}{c}{ Solo/cultura } & Código & \multicolumn{4}{c}{$\mathrm{pH}$} \\
\cline { 4 - 7 } & & & 1 & 2 & 3 & Média \\
\hline \multirow{2}{*}{1} & Cupuaçu (Theobroma grandiflorum & INPA-M1 & 3,8 & 4,1 & 3,9 & 3,9 \\
& (Willd. ex Spreng.) Schum) & & & & \\
& Coco (Cocos nucifera L.) & INPA-M2 & 5,8 & 4,7 & 5,3 & 5,3 \\
\hline \multirow{2}{*}{2} & Biribá (Rollinia mucosa (Jacq.) Baill.) & INPA-M3 & 5,1 & 4,4 & 4,3 & 4,6 \\
& Pupunha (Bactris gasipae HBK) & INPA-M4 & 5,8 & 4,7 & 4,6 & 5,0 \\
& Manga (Mangifera indica L.) & INPA-M5 & 3,8 & 4,3 & 3,8 & 4,0 \\
\hline \multirow{2}{*}{3} & Urucum (Bixa orellana L.) & INPA-M6 & 4,1 & 3,9 & 3,8 & 3,9 \\
& Caju (Anacardium occidentale L.) & INPA-M7 & 3,9 & 3,8 & 4,1 & 3,9 \\
& Açaí (Euterpe oleracea Mart.) & INPA-M8 & 3,9 & 4,0 & 3,9 & 3,9 \\
\hline 4 & Piquiá (Caryocar villosum (Aubl.) & INPA-M9 & 3,9 & 3,7 & 3,5 & 3,7 \\
\hline 5 & Ingá (Inga edulis Mart.) & INPA-M10 & 4,0 & 4,1 & 3,9 & 4,0 \\
\hline
\end{tabular}

Foram retiradas subamostras de $60 \mathrm{~g}$ de solo de cada amostra, para serem usadas como fonte de inóculo para plantas de caupi (Vigna unguiculata L. Walp., cultivar IPEAN - V69), e para a avaliação da população de rizóbio, em um experimento conduzido em casa de vegetação, na Coordenação de Pesquisa em Ciências Agronômicas do INPA, em Manaus.

As subamostras de solo foram colocadas sobre e no centro da areia estéril, autoclavada a $120^{\circ} \mathrm{C}$ por duas horas, em vasos esterilizados, com capacidade para $3 \mathrm{~kg}$, e foram semeadas oito sementes de caupi por vaso, para que, ao germinarem, as raízes das plantas entrassem em contato com isolados de rizóbios presentes no solo. No sétimo dia após a germinação fez-se o desbaste, deixando-se três plantas por vaso. A irrigação foi feita de acordo com a necessidade, usando-se de uma solução nutritiva, ácida e álica, $\mathrm{pH} 4,5+2 \mathrm{cmol}_{\mathrm{C}} \mathrm{L}^{-1}$ de Al, modificada (Specht et al., 1965; Smith et al., 1983), segundo Oliveira (1988), para representar as condições encontradas na maioria dos solos da Amazônia, em relação a esses aspectos.

No período da floração, as plantas foram seccionadas na base do caule, e levadas para secar a $60^{\circ} \mathrm{C}$ até peso constante, para determinação da biomassa seca da parte aérea (BSPA). As raízes foram coletadas para determinação do número de nódulos (NN). A biomassa seca dos nódulos (BSN) foi obtida após secagem do material, da mesma forma que para a parte aérea.

O delineamento experimental utilizado foi o de blocos ao acaso com 11 tratamentos, 10 referentes às diferentes áreas de coleta de solo, consideradas como fontes de inóculos, mais um tratamento testemunha, com os vasos que continham areia estéril, sem amostra de solo; foram utilizadas três repetições por tratamento. Foi realizada a análise de variância ( $5 \%$ e $1 \%$ ), e o teste de Tukey (5\%) para se verificar o contraste entre as médias.

\section{Isolamento de rizóbio e teste de tolerância à aci- dez e ao alumínio tóxico}

Foram selecionados, das raízes das plantas do experimento anterior, de três a cinco dos maiores nódulos com coloração intensa avermelhada, o que indica presença de leg-hemoglobina e nitrogenase. Os isolamentos de rizóbio foram feitos segundo a metodologia de Somasegaran \& Hoben (1985). De cada nódulo foi obtido um isolado, que foi repicado para o meio extrato de levedura, manitol e ágar (YMA) (Vincent, 1970), com $\mathrm{pH}$ 6,5, em placa de Petri. Os isolados foram purifica- 
dos e armazenados em tubos de ensaio com YMA, à temperatura de $28^{\circ} \mathrm{C}$.

Para a avaliação da tolerância à acidez e ao alumínio tóxico, os isolados foram transferidos para o meio YMA, com pH 4,5, com pH 4,5 + 2,0 cmol $_{\mathrm{c}} \mathrm{L}^{-1}$ de Al e com pH 6,5. O alumínio foi adicionado na forma de $\mathrm{AlCl}_{3}$. Foram utilizadas quatro repetições para cada meio, utilizando-se o método de riscagem proposto por Oliveira \& Magalhães (1999) (Figura 1); cada placa foi marcada ao meio, e cada metade da placa continha uma repetição, estabelecendo-se então, duas repetições por placa de Petri. Com o objetivo de verificar a alteração do $\mathrm{pH}$ do meio pelas bactérias, foram acrescentados os indicadores bromocresol verde $\left(20 \mathrm{~mL} \mathrm{~L}^{-1}\right)$ nos meios com $\mathrm{pH} 4,5$ e pH 4,5 + Al, e azul de bromotimol $\left(5 \mathrm{~mL} \mathrm{~L}^{-1}\right)$ no meio com $\mathrm{pH} 6,5$.

As avaliações foram feitas a cada três dias, durante um período de 18 dias, em que as bactérias foram mantidas em laboratório a uma temperatura de $23^{\circ} \mathrm{C}$ a $28^{\circ} \mathrm{C}$. De acordo com o desenvolvimento das colônias, nas quatro zonas da placa (Figura 1), foram dados valores para o crescimento, para cada isolado, com variação de 1 (sem crescimento visível na placa), a 4 (máximo crescimento em todas as zonas), segundo a escala apresentada na Figura 1. Com base no crescimento em placas de Petri, os isolados foram classificados como sensíveis (crescimento em placas entre 1 e 2), medianamente tolerantes (crescimento em placas entre 2,06 e 3), ou tolerantes (crescimento em placas entre 3,06 e 4).

\section{Teste de solubilização de fosfatos de cálcio e de alumínio}

Foram instalados dois experimentos, um para verificar a capacidade dos isolados de solubilizar fosfato de cálcio, e outro para a solubilização de fosfato de alumí-

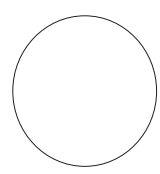

1,00

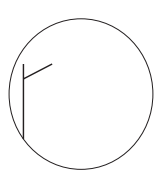

1,25

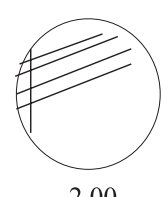

2,00

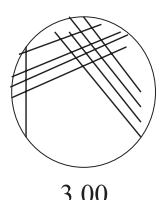

3,00

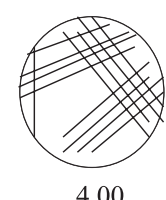

4,00
Figura 1. Valores de crescimento para os isolados de rizóbios, nos respectivos tratamentos em placas de Petri, com meio YMA (Oliveira \& Magalhães, 1999). Zona 1: uma linha, riscando-se várias vezes em ambas direções; Zona 2: quatro linhas riscadas em apenas uma direção; Zona 3 e 4: da mesma forma que a Zona 2. nio. No primeiro experimento foi utilizado o meio de cultura desenvolvido por Sylvester-Bradley et al. (1982), com $10 \mathrm{~g}$ de glicose, $2 \mathrm{~g}$ de extrato de levedura e $18 \mathrm{~g}$ de ágar por litro. Foram acrescentadas as soluções A, com 5 g de $\mathrm{K}_{2} \mathrm{HPO}_{4}$ em $50 \mathrm{~mL}$ de água, e B, com $10 \mathrm{~g}$ de $\mathrm{CaCl}_{2}$ em $100 \mathrm{~mL}$ de água, para a formação do fosfato de cálcio precipitado. Em seguida, ajustou-se o pH para 6,5. No segundo experimento foi utilizado um meio, com pH 4,5, para verificar a solubilização de fosfato de alumínio, com $10 \mathrm{~g}$ de manitol, $2 \mathrm{~g}$ de extrato de levedura, $6 \mathrm{~g}$ de $\mathrm{K}_{2} \mathrm{HPO}_{4}$ e $18 \mathrm{~g}$ de ágar por litro, acrescido de 5,34 g de $\mathrm{AlCl}_{3}$, para formar o precipitado de fosfato de alumínio. $\mathrm{O} \mathrm{AlCl}_{3}$ foi autoclavado, separadamente, antes da sua adição ao meio.

Os isolados de rizóbios, crescidos em meio YMA $(\mathrm{pH}$ 6,5) foram repicados para os dois meios de solubilização com o auxílio de uma alça de platina; retirou-se uma porção do isolado armazenado em tubo de ensaio e realizou-se um leve toque no meio de cultura para cada colônia. Foram estabelecidas cinco colônias por placa, e duas placas por isolado.

O diâmetro do halo de solubilização, percebido como uma área translúcida em torno da colônia, foi medido a cada três dias, utilizando-se um paquímetro digital, por um período de 18 dias. A partir dessas medidas, foram obtidos os Índices de Solubilização (IS), para cada isolado, pela fórmula: IS $=\phi$ Halo $(\mathrm{mm}) / \phi$ Colônia $(\mathrm{mm})$ (Berraquero et al., 1976).

Com base nos índices, os isolados foram classificados por capacidade de solubilização como: baixa (IS $<2$ ), média $(2 \leq \mathrm{IS}<4)$ e alta (IS $>4)$. Foram também classificados como precoces, quando o início da solubilização se deu até o terceiro dia; tardios, com início da solubilização a partir do terceiro dia; e não solubilizadores, aqueles que não apresentaram solubilização visível até o 18 o dia de avaliação.

\section{Resultados e Discussão}

Todos os parâmetros avaliados foram influenciados pelas fontes de inóculos utilizadas, de acordo com a análise de variância $(p \leq 0,01)$. O rendimento de biomassa seca da parte aérea do caupi foi muito baixo em todos os tratamentos, principalmente na testemunha e quando se utilizou o inóculo INPA-M5 (Tabela 2). O inóculo INPA-M10 foi o único que proporcionou rendimento de matéria seca significativamente superior a esses dois tratamentos. Esses resultados estão de acordo com os obtidos por Fernandes \& Fernandes (2000), que verifi- 
caram o efeito de estirpes de rizóbio sobre a matéria seca do feijão guandu. A baixa eficiência das fontes de inóculo, em proporcionar aumento de matéria seca, pode estar relacionada com a baixa capacidade de fixação do $\mathrm{N}$ atmosférico da população de rizóbio, presente nas amostras de solo.

Os isolados INPA-M7 e INPA-M9 não foram capazes de formar nódulos no caupi (Tabela 2). Ao se analisar as Tabelas 1 e 2, nota-se que a maioria dos inóculos foi oriunda de solos com pH abaixo de 4 (3,7 a 3,9). Isto indica que a atividade de íons de $\mathrm{H}^{+}$ou $\mathrm{Al}^{3+}$ pode estar limitando a sobrevivência dos rizóbios nas condições naturais (Bonetti et al., 1984).

Quanto à biomassa seca dos nódulos, não houve diferença significativa entre os isolados (Tabela 2). Os isolados que formaram maiores quantidades de nódulos proporcionaram maiores valores de biomassa seca dos nódulos (Tabela 2), tendo sido detectada uma correlação significativa entre o número e a massa dos nódulos $(r=0,74)$.

Todos os isolados provenientes dos isolados de rizóbios avaliados no teste de infectividade ocasionaram acidificação do meio de cultura com $\mathrm{pH}$ 6,5. Apenas 11 isolados alcalinizaram o meio com $\mathrm{pH} 4,5$, e foram, ainda, capazes de alcalinizar o meio na presença do alumínio tóxico. A acidificação do meio de cultura com $\mathrm{pH}$ 4,5 foi observada na presença de 14 isolados, dos quais 12 também acidificaram esse meio em presença do alumínio tóxico.

Tabela 2. Biomassa seca da parte aérea (BSPA), número de nódulos (NN) e biomassa seca dos nódulos (BSN) de raízes do feijão caupi (Vigna unguiculata (L.) Walp.), colonizadas por rizóbios provenientes de solos do Município de Iranduba, $\mathrm{AM}^{(1)}$.

\begin{tabular}{lccc}
\hline Inóculos & BSPA $\left(\mathrm{g} \mathrm{vaso}^{-1}\right)$ & $\mathrm{NN} /$ vaso & $\mathrm{BSN}\left(\mathrm{mg} \mathrm{vaso}^{-1}\right)$ \\
\hline INPA-M7 & $1,63 \mathrm{ab}$ & $0 \mathrm{a}$ & $0 \mathrm{~b}$ \\
INPA-M9 & $1,75 \mathrm{ab}$ & $0 \mathrm{a}$ & $0 \mathrm{~b}$ \\
INPA-M4 & $2,02 \mathrm{ab}$ & $33 \mathrm{a}$ & $106 \mathrm{a}$ \\
INPA-M10 & $2,10 \mathrm{a}$ & $37 \mathrm{a}$ & $92 \mathrm{a}$ \\
INPA-M1 & $1,78 \mathrm{ab}$ & $12 \mathrm{a}$ & $54 \mathrm{ab}$ \\
INPA-M2 & $1,86 \mathrm{ab}$ & $18 \mathrm{a}$ & $62 \mathrm{ab}$ \\
INPA-M3 & $1,84 \mathrm{ab}$ & $20 \mathrm{a}$ & $73 \mathrm{ab}$ \\
INPA-M8 & $1,55 \mathrm{ab}$ & $11 \mathrm{a}$ & $34 \mathrm{ab}$ \\
INPA-M5 & $1,46 \mathrm{~b}$ & $36 \mathrm{a}$ & $49 \mathrm{ab}$ \\
INPA-M6 & $1,84 \mathrm{ab}$ & $14 \mathrm{a}$ & $33 \mathrm{ab}$ \\
Testemunha & $1,50 \mathrm{~b}$ & $0 \mathrm{a}$ & $0 \mathrm{~b}$ \\
\hline CV $(\%)$ & 11 & 54 & 59 \\
\hline
\end{tabular}

(1)Médias seguidas da mesma letra, na coluna, não diferem entre si pelo teste de Tukey a $5 \%$ de probabilidade.
Os isolados INPA-M1b, INPA-M1c, INPA-M3d, INPA-M4c, INPA-M5b e INPA-M5d apresentaram crescimento menor que três no $\mathrm{pH} 6,5$, bem como na presença da acidez e do alumínio tóxico, aos 18 dias de crescimento. Isto indica que algum fator, excluindo o $\mathrm{pH}$, deve ter interferido no crescimento desses isolados. O baixo crescimento no meio padrão é um indicativo de que esses isolados apresentam dificuldades de adaptação ao meio de cultura, característica indesejável para indicá-los como inoculantes. Entre os isolados que apresentaram alto crescimento no $\mathrm{pH} \mathrm{6,5,} \mathrm{aos} 18$ dias de avaliação, dez apresentaram o crescimento máximo estabilizado já no terceiro dia. Em uma avaliação mais rigorosa, o tempo de crescimento pode também ser usado para a seleção. Os isolados que, na presença da acidez, apresentaram maior crescimento, em menor período de tempo, podem ser considerados como mais tolerantes à acidez.

O crescimento dos isolados nos meios aumentou com o tempo de exposição. Do total de 30 isolados, $43 \%$ se comportaram como sensíveis, e $57 \%$ como tolerantes à acidez e à acidez mais alumínio (Tabela 3). Todos os isolados que apresentaram sensibilidade ao alumínio tam-

Tabela 3. Tolerância à acidez e ao alumínio tóxico dos isolados de rizóbios, oriundos de solos agrícolas do Município de Iranduba, AM.

\begin{tabular}{|c|c|c|c|c|c|c|c|c|c|}
\hline \multirow[t]{3}{*}{ Isolado } & \multicolumn{3}{|c|}{$3^{\circ} \mathrm{Dia}$} & \multicolumn{3}{|c|}{$6^{0} \mathrm{Dia}$} & \multicolumn{3}{|c|}{$8^{\circ} \mathrm{Dia}$} \\
\hline & $\mathrm{pH}$ & $\mathrm{pH}$ & $\mathrm{pH} \mathrm{4,5}$ & $\mathrm{pH}$ & $\mathrm{pH}$ & $\mathrm{pH} \mathrm{4,5}$ & $\mathrm{pH}$ & $\mathrm{pH}$ & $\mathrm{pH} 4,5$ \\
\hline & 4,5 & 6,5 & $+\mathrm{Al}$ & 4,5 & 6,5 & $+\mathrm{Al}$ & 4,5 & 6,5 & $+\mathrm{Al}$ \\
\hline INPA-M1a & 1,25 & 4,00 & 1,00 & 1,25 & 4,00 & 1,00 & 1,25 & 4,00 & 1,00 \\
\hline INPA-M1b & 1,00 & 1,13 & 1,00 & 1,00 & 4,00 & 1,00 & 1,00 & 1,25 & 1,00 \\
\hline INPA-M1c & 1,00 & 1,13 & 1,00 & 1,00 & 4,00 & 1,00 & 1,00 & 1,25 & 1,00 \\
\hline INPA-M1d & 2,00 & 1,50 & 2,00 & 3,50 & 4,00 & 3,00 & 4,00 & 4,00 & 4,00 \\
\hline INPA-M2a & 4,00 & 3,50 & 4,00 & 4,00 & 3,50 & 4,00 & 4,00 & 3,50 & 4,00 \\
\hline INPA-M2b & 1,00 & 4,00 & 1,00 & 1,00 & 4,00 & 1,00 & 1,00 & 4,00 & 1,00 \\
\hline INPA-M2c & 1,13 & 3,50 & 1,00 & 1,13 & 3,50 & 1,13 & 1,13 & 3,50 & 1,13 \\
\hline INPA-M2d & 3,25 & 2,00 & 2,75 & 4,00 & 4,00 & 4,00 & 4,00 & 4,00 & 4,00 \\
\hline INPA-M3a & 1,75 & 4,00 & 3,88 & 3,63 & 4,00 & 4,00 & 3,75 & 4,00 & 4,00 \\
\hline INPA-M3b & 3,69 & 3,88 & 4,00 & 4,00 & 4,00 & 3,75 & 4,00 & 4,00 & 4,00 \\
\hline INPA-M3c & 3,63 & 4,00 & 4,00 & 4,00 & 4,00 & 4,00 & 4,00 & 4,00 & 4,00 \\
\hline INPA-M3d & 1,00 & 1,00 & 1,00 & 1,00 & 1,00 & 1,00 & 1,00 & 1,00 & 4,00 \\
\hline INPA & 00 & 3,00 & 2,00 & 4,00 & 3,13 & 2,88 & 3,56 & 3,19 & 3,63 \\
\hline INPA & 4,00 & 3,50 & 3,88 & 4,00 & 4,00 & 4,00 & 4,00 & 4,00 & 4,00 \\
\hline INP & 1,00 & 1,00 & 1,00 & 1,00 & 2,00 & 1,00 & 1,00 & 2,00 & 1,00 \\
\hline INP & 1,00 & 4,00 & 1,00 & 1,00 & 4,00 & 1,00 & 1,00 & 4,00 & 1,00 \\
\hline INPA & 2,50 & 3,00 & 2,00 & 3,44 & 4,00 & 3,00 & 4,00 & 4,00 & 3,75 \\
\hline INPA- & 4,00 & 4,00 & 4,00 & 4,00 & 4,00 & 4,00 & 4,00 & 4,00 & 4,00 \\
\hline INPA & 1,00 & 1,00 & 1,00 & 1,00 & 2,00 & 1,00 & 1,00 & 2,00 & 4,00 \\
\hline M5c & 1,00 & 3,25 & 1,00 & 1,00 & 3,25 & 1,00 & 1,00 & 3,25 & 1,25 \\
\hline NPA-M5d & 1,00 & 1,00 & 1,00 & 1,00 & 1,00 & 1,00 & 1,00 & 1,00 & 1,00 \\
\hline INPA-M6a & 2,06 & 2,50 & 2,00 & 2,31 & 4,00 & 4,00 & 4,00 & 4,00 & 4,00 \\
\hline INPA-M6b & 3,38 & 4,00 & 3,25 & 4,00 & 4,00 & 3,81 & 4,00 & 4,00 & 4,00 \\
\hline INPA-M6c & 1,00 & 4,00 & 1,50 & 1,00 & 4,00 & 2,00 & 1,00 & 4,00 & 1,00 \\
\hline INPA-M8a & 1,00 & 3,50 & 1,69 & 1,00 & 4,00 & 2,00 & 2,00 & 4,00 & 3,00 \\
\hline INPA-M10a & 3,81 & 4,00 & 4,00 & 3,81 & 4,00 & 4,00 & 4,00 & 4,00 & 4,00 \\
\hline INPA-M10b & 2,75 & 4,00 & 2,88 & 3,44 & 4,00 & 3,75 & 3,63 & 4,00 & 4,00 \\
\hline & 4,00 & 3,00 & 3,63 & 4,00 & 3,00 & 3,69 & 4,00 & 3,00 & 4,00 \\
\hline & 3,25 & 1,25 & 2,94 & 4,00 & 1,50 & 4,00 & 4,00 & 1,25 & 1,00 \\
\hline INPA-M10e & 1,50 & 2,00 & 2,00 & 2,13 & 4,00 & 2,50 & 4,00 & 4,00 & 1,00 \\
\hline
\end{tabular}


bém se comportaram dessa maneira em relação ao pH 4,5. O isolado INPA-M10d foi o único, entre os tolerantes à acidez, que não apresentou crescimento satisfatório no meio com alumínio. Isto reforça a idéia de que a tolerância à acidez não significa tolerância ao alumínio (Marriel, 1984); assim, a identificação de isolados resistentes à acidez, isoladamente, não parece ser um procedimento adequado para a seleção do rizóbio, para os solos ácidos e álicos da Amazônia.

No terceiro dia de avaliação, foi observada a estabilização do crescimento na zona mais diluída (Zona 4) no $\mathrm{pH}$ 4,5, para os isolados INPA-M2a, INPA-M4b, INPAM5a e INPA-M10c (Tabela 3). Oliveira \& Magalhães (1999) utilizaram essa mesma metodologia e detectaram a estabilização do crescimento máximo no 9o dia de avaliação, apenas para três isolados de rizóbios oriundos da Amazônia.

Os isolados INPA-M2a, INPA-M3b, INPA-M3c, INPA-M5a e INPA-M10a, considerados tolerantes ao alumínio tóxico, apresentaram crescimento máximo e estabilizado no $3^{3}$ o dia de avaliação (Tabela 3). Conseqüentemente, o tempo de crescimento pode também ser usado para a seleção, da mesma forma como se procedeu com os isolados tolerantes à acidez.

Os isolados tolerantes ao alumínio parecem ter acionado dois mecanismos diferentes de tolerância ao alumínio tóxico. Nove isolados, entre os tolerantes, INPAM2a, INPA-M2d, INPA-M1d, INPA-M3b, INPA-M6a, INPA-M6b, INPA-M10b, INPA-M10d e INPA-M10e, alcanilizaram o meio, o que propiciou a neutralização do alumínio tóxico, diminuindo seu efeito. Os demais isolados tolerantes a esse metal, INPA-M3a, INPA-M3c, INPA-M4a, INPA-M4b, INPA-M4e, INPA-M5a, INPA-M10a e INPA-M10c, acidificaram o meio com alumínio, corroborando os resultados obtidos por Kawai et al. (2000), que também observaram tolerância e diminuição do pH em presença de alumínio. Segundo os mesmos autores, pode ser que esta diminuição de $\mathrm{pH}$ tenha causado uma modificação da forma mais prejudicial do alumínio, que é a monomérica, para uma outra menos tóxica.

Entre os isolados avaliados, $57 \%$ apresentaram capacidade de solubilizar o fosfato de cálcio (Tabela 4). No entanto, houve pouca variação quanto ao potencial de solubilização desses isolados. Todos apresentaram baixa capacidade de solubilizar o fosfato de cálcio até os 18 dias de avaliação; o índice de solubilização variou de 1 a 1,26. Quanto ao tempo de avaliação, apenas os isolados INPA-M1a, INPA-M2c, INPA-M5a, INPAM5d, INPA-M6d e INPA-M10c se comportaram como tardios, iniciando a solubilização no 60 dia de repicagem. Os demais se comportaram como precoces, iniciando a solubilização no 3o dia de crescimento em meio de cultura.

Entre os isolados avaliados, 57\% apresentaram capacidade de solubilizar o fosfato de alumínio (Tabela 4). Houve pouca variação quanto ao potencial de solubilização desses isolados, da mesma forma como ocorreu para a solubilização do fosfato de cálcio. Todos apresentaram baixa capacidade de solubilizar o fosfato de alumínio até os 18 dias de avaliação, cujo índice de solubilização variou de 1,06 a 1,24. Esses valores estão muito próximos dos obtidos por Silva Filho \& Vidor (2000) com alguns isolados de fungos do solo. Quanto ao inícío da solubilização, apenas o isolado INPA-M5c se comportou como tardio.

Era esperada maior proporção desses solubilizadores, em relação aos que solubilizam fosfato de cálcio, tendose em vista que o fosfato de alumínio é a forma predominante nos solos da região (Raij, 1991). Os trabalhos que envolvem a solubilização de fosfato de alumínio são escassos, e nenhum trabalho até o momento foi realizado para investigar o papel da população de rizóbios nesse processo, embora, em condições tropicais e subtropicais, sejam as formas predominantes de fosfato.

Tabela 4. Índice de solubilização de fosfato de alumínio (IS), de isolados de rizóbios obtidos de solos agrícolas de Iranduba, AM.

\begin{tabular}{|c|c|c|c|c|}
\hline \multirow[t]{3}{*}{ Isolado } & \multicolumn{4}{|c|}{ IS (mm) } \\
\hline & \multicolumn{2}{|c|}{$\mathrm{P}-\mathrm{Ca}^{(2)}$} & \multicolumn{2}{|c|}{$\mathrm{P}-\mathrm{Al}^{(3)}$} \\
\hline & Inicial & Final & Inicial & Final \\
\hline INPA-M1a & 1,01 & 1,19 & 1,06 & 1,21 \\
\hline INPA-M1b & 1,31 & 1,61 & 1,05 & 1,17 \\
\hline INPA-M1c & 1,00 & 1,01 & 1,04 & 1,14 \\
\hline INPA-M1d & 1,64 & 1,21 & 1,04 & 1,05 \\
\hline INPA-M3a & 1,10 & 1,10 & 1,00 & 1,12 \\
\hline INPA-M3b & 1,00 & 1,00 & 1,06 & 1,08 \\
\hline INPA-M3c & 1,29 & 1,16 & 1,10 & 1,05 \\
\hline INPA-M4a & 1,00 & 1,00 & 1,07 & 1,24 \\
\hline INPA-M4b & 1,41 & 1,26 & 1,12 & 1,15 \\
\hline INPA-M4c & 1,02 & 1,15 & 1,00 & 1,12 \\
\hline INPA-M4d & 1,09 & 1,09 & 1,10 & 1,10 \\
\hline INPA-M5b & 1,00 & 1,00 & 1,09 & 1,15 \\
\hline INPA-M5c & 1,19 & 1,19 & 1,15 & 1,08 \\
\hline INPA-M5d & 1,00 & 1,00 & 1,02 & 1,12 \\
\hline INPA-M6b & 1,00 & 1,02 & 1,10 & 1,06 \\
\hline INPA-M8a & 1,00 & 1,01 & 1,04 & 1,08 \\
\hline INPA-M10c & 1,00 & 1,00 & 1,04 & 1,09 \\
\hline
\end{tabular}

(1)IS = $\phi$ Halo $(\mathrm{mm}) / \phi$ Colônia $(\mathrm{mm}) .{ }^{(2)}$ Fosfato de cálcio. ${ }^{(3)}$ Fosfato de alumínio. 
Os dados da Tabela 4 evidenciam que $60 \%$ dos isolados que solubilizaram o fosfato de cálcio, também solubilizaram o fosfato de alumínio. Esse resultado diverge dos encontrados por Toro et al. (1996) e Silva Filho \& Vidor (2000), que identificaram uma baixa ocorrência de solubilizadoras de fosfato de cálcio que também solubilizam fosfato de alumínio.

\section{Conclusões}

1. Os isolados de rizóbios existentes nas amostras de solos são ineficientes em proporcionar incremento de biomassa seca da parte aérea no caupi.

2. Os isolados que apresentam sensibilidade ao alumínio também se comportam dessa maneira em relação ao $\mathrm{pH} 4,5$.

3. Os isolados apresentam diferenças nos mecanismos de tolerância ao alumínio tóxico.

4. Os isolados capazes de solubilizar o fosfato de cálcio e o fosfato de alumínio apresentam baixo índice de solubilização.

\section{Agradecimentos}

Ao CNPq pela concessão de Bolsa a Luiz Antonio de Oliveira; ao BASA S/A pelo financiamento deste trabalho.

\section{Referências}

BERRAQUERO, F.R.; BAYA, A.M.; CORMENZANA, A.R. Establecimiento de índices para el estudio de la solubilización de fosfatos por bacterias del suelo. Ars Pharmaceutica, v.17, p.399406, 1976.

BONETTI, R.; OLIVEIRA, L.A.; MAGALHÃES, F.M.M. Rhizobium spp. populations, and mycorrhizal associations in some plantations of forest tree species. Pesquisa Agropecuária Brasileira, v.19, p.137-142, 1984.

FERNANDES, M.F.; FERNANDES, R.P.M. Seleção inicial e caracterização parcial de rizóbios de tabuleiros costeiros quando associados ao guandu. Revista Brasileira de Ciência do Solo, v.24, p.321-327, 2000.

HUNGRIA, M.; VARGAS, M.A.T. Environmental factors affecting grain legumes in the tropics, with an emphasis on Brazil. Field Crops Research, v.65, p.151-164, 2000.

KAWAI, F.; ZHANG, D.; SUGIMOTO, M. Isolation and characterization of acid and Al-tolerant microorganisms. FEMS Microbiology Letters, v.189, p.143-147, 2000.

MARRIEL, I.E. Efeitos de fatores limitantes sobre o crescimento de Rhizobium japonicum (Kirchner) Buchanan e de soja (Glycine max (L.) Merrill). 1984. 114p. Dissertação (Mestrado) Universidade Federal de Viçosa, Viçosa.

OCTIVE, J.C.; JOHSON, A.C.; WOOD, M. Effects of previous aluminium exposure on motility and nodulation by Rhizobium and
Bradyrhizobium. Soil Biology \& Biochemistry, v.26, p.1477-1482, 1994.

OLIVEIRA, L.A. de. Competitive ability of Rhizobium leguminosarum bv. phaseoli strains. 1988. 125p. Thesis (Ph. D.) University of Minnesota, Minnesota.

OLIVEIRA, L.A. de; MAGALHÃES, H.P. de. Quantitative evaluation of acidity tolerance of root nodule bacteria. Revista de Microbiologia, v.30, p.203-208, 1999.

RAIJ, B. van. Fertilidade do solo e adubação. São Paulo: Ceres, 1991. 347p.

RAMOS, M.L.G.; MAGALHÃES, N.F.M.; BODDEY, R.M. Native and inoculated rhizobia isolated from field grown Phaseolus vulgaris: effects of limming and acid soil on antibiotic resistance. Soil Biology \& Biochemistry, v.19, p.179-185, 1987.

SANCHEZ, P.A.; BANDY, D.E.; VILLACHICA, J.H.; NICHOLAIDES, J.J. Amazon basin soils: management for continuous crop production. Science, v.216, p.821-827, 1982.

SILVA FILHO, G.N.; VIDOR, C. Solubilização de fosfato por microorganismos na presença de fontes de carbono. Revista Brasileira de Ciência do Solo, v.24, p.311-319, 2000.

SMITH, G.S.; JOHNSON, C.M.; CORNFORTH, I.S. Comparison of nutrient solutions for growth of plants in sand culture. New Phytologist, v.94, p.537-548, 1983.

SOMASEGARAN, P.; HOBEN, H.J. Methods in legumerhizobium technology. Hawaii: NifTAL Project; MIRCEN, 1985. 365p.

SPECHT, A.W.; ERDMAN, L.W.; MEANS, V.M.; RERNICKY, J.W. Effect of nutrition on Trifolium hirtum inoculated with Rhizobium trifolii. Soil Science Society of America Proceedings, v.29, p.489495, 1965.

STARKANOVA, G.; VORISEK, K.; MIKANOVA, O.; RONDOVA, D. P-solubilization activity of Rhizobium species strains. Rostlinna Vyroba, v.45, p.403-406, 1999.

SYLVESTER-BRADLEY, R.; ASAKAWA, N.; LA TORRACA, S.; MAGALHÃES, F.M.M.; OLIVEIRA, L.A.; PEREIRA, R.M. Levantamento quantitativo de microrganismos solubilizadores de fosfato na rizosfera de gramíneas e leguminosas forrageiras na Amazônia. Acta Amazonica, v.12, p15-22, 1982.

TORO, M.; AZCÓN, R.; HERRERA, R. Effects on yield and nutrition of mycorrhizal and nodulated Pueraria phaseoloides exerted by P-solubilizing rhizobacteria. Biology and Fertility Soils, v.21, p.23-29, 1996.

VINCENT, J.M. A manual for practical study of root nodule bacteria. New York: Blackwell Scientific Publication, 1970. 140p. (IBP Handbook, 15).

WATKIN, E.L.J.; O’HARA, G.W.; HOWIESON, J.G.; GLENN, A.R. Identification of tolerance to soil acidity in inoculant strains of Rhizobium leguminosarum bv. trifolii. Soil Biology \& Biochemistry, v.32, p.1393-1403, 2000.

WOOD, M. A mechanism of aluminium toxicity to soil bacteria and possible ecological implications. Plant and Soil, v.171, p.63-69, 1995.

Recebido em 7 de maio de 2004 e aprovado em 22 de fevereiro de 2005 